Journal of Computer Science and Technology Studies (JCSTS))

ISSN: $2709-104 \mathrm{X}$

DOI: $10.32996 /$ jcsts

Journal Homepage: www.al-kindipublisher.com/index.php/jcsts

\title{
Design of Online-Based Tourism Ticket Purchase System
}

\author{
Salsabila Safira Azalea \\ Department of Informatics, Faculty of Industrial Technology, Gunadarma University, Jl. Margonda Raya No. 100, Pondok Cina, \\ Beji District, Depok City, West Java \\ $\square$ Corresponding Author: Salsabila Safira Azalea, E-mail: salsabilasazalea@gmail.com
}

\section{ARTICLE INFORMATION}

Received: 04 October 2021

Accepted: 21 November 2021

Published: 07 December 2021

DOI: $10.32996 / j$ csts.2021.3.2.6

\section{KEYWORDS}

System, Web, Tourism, Online

Ticketing

\section{ABSTRACT}

In this day and age, technology development is very rapid, especially the development of the internet which greatly facilitates human work in various fields such as the military, offices, factories, medical, and entertainment. Entertainment is something that is very much needed for some people because of the density of activities, for many recreational places have started to use all their activities through the web, one of which is in terms of promotions and ticket purchases. Here the author makes a system where ticket purchases can be made via the web. Starting from designing the existing displays by coding with the programming language that has been determined, for client-side namely HTML, CSS (Bootstrap), and JavaScript as well as server-side using PHP and MySQL. After that, it is implemented using a computer. This writing aims to build a ticket purchase information system and tourism promotion that is simple and easy to use.

\section{Introduction}

Along with the development of an increasingly modern and increasingly advanced era, the world has experienced many significant changes and has greatly influenced the development of humans and the earth. This is very biased and cannot be avoided by humans because, with the progress of this era, humans increasingly need all kinds of needs, both temporary and essential for their lives. One technology that can help human life is a web-based system. This web-based system is starting to develop rapidly at this time and has been used in various fields, one of which is tourism. Tourism is something that is very much needed for some people because of the density of activities, for that there are many choices of recreational areas as a means of entertainment. In this case, the web-based system is very helpful for the community so that they can choose the desired recreation area without the need to search directly to the place.

Web-based systems in the field of tourism are commonly used for the promotion and purchase of tickets from the tourist attractions themselves. Gradually the culture of buying tickets began to shift from the conventional way to a more modern one with the help of the internet or commonly known as online booking. Currently, ticket reservations can be made anytime and anywhere via a computer or smartphone connected to the internet. This is very helpful for tourists to get various information about the facilities provided and the prices offered, all of which can be accessed and obtained easily. Web-based ticket purchases are very helpful for both local and foreign tourists. Because it can avoid buying tickets from brokers which will be detrimental and time is wasted.

\section{Theory Basis}

A. Tourism

Law no. 10 of 2009 explains that tourism is a variety of tourism activities and is supported by various facilities and services provided by the community, businessmen, government, and local governments. (Muljadi, 2009)

Copyright: (C) 2021 the Author(s). This article is an open access article distributed under the terms and conditions of the Creative Commons Attribution (CC-BY) 4.0 license (https://creativecommons.org/licenses/by/4.0/). Published by Al-Kindi Centre for Research and Development, London, United Kingdom. 
B. Information Systems

Information systems according to Robert A. Leitch and K. Roscoe Davis is a system within an organization that brings together daily transaction processing needs, supports operations, is managerial and strategic activities of an organization, and provides certain outside parties with reports -required reports.

C. Website

A website can be defined as a collection of pages that are used to publish information in the form of text, images, and other multimedia programs in the form of sound animation and or a combination of all of them, both static and dynamic, which are interrelated between one page and a page which is often referred to as a website. hyperlinks (Arief, 2006).

D. PHP

PHP is a server-side scripting language designed for web development (Alatas, 2013). In addition, PHP can also be used as a general programming language. PHP was developed in 1995 by Rasmus Lerdorf and is now managed by The PHP Group. Variable data types in PHP there are 8 types of variable data including Integer, Float, Boolean, Null, String, Array, Object and Resource. PHP will automatically convert or determine the data type of the variable based on the value it stores.

E. HTML

HyperText Markup Language (HTML) is a markup language used to create a web page, display various information in an Internet web browser, and simple hypertext formatting written into ASCII format files in order to produce an integrated form display (Raharjo, 2016).

F. CSS

CSS stands for Cascading Style Sheet. That is in the form of a document that can set the style of a web page or other document with a certain order of commands that have been determined (Hidayatullah and Kawistara, 2015).

G. Bootstrap

Understanding Bootstrap is a library (library/collection of functions) from the CSS Framework which was created specifically for the front-end development part of a website (Alatas, 2013). Bootstrap is a framework for building responsive web designs. That is, the web display created by bootstrap will adjust the size of the layer and browser that we use both on the desktop, tablet, or mobile device. With bootstrap, we can also build dynamic or static webs (Arief, 2011).

H. MySQL

MySQL is a multi-stream, multi-user SQL or DBMS database management system software with approximately 6 million installations worldwide. MySQL AB makes MySQL available as free software under the GNU General Public License (GPL) (Djaelangkara, Sengkey, and Lantang, 2015).

I. UML

Unified Modeling Language (UML) is a standard modeling language for software and system development (Haviludin, 2011). In system design, the model is one of the important reasons for managing complexity. Modeling will help in building the system, creating boundaries so that you can focus on managing documents. UML is often used in the development of a system that provides standards in the design of a system model.

J. Navigation Structure

The navigation structure is the flow used in the created application. Before compiling a multimedia application into software, it must be determined in advance what flow will be used in the application created. The basic form of the navigation structure commonly used in the process of making multimedia applications there are 4 (four) kinds, namely linear, hierarchical, non-linear, and mixed navigation structures.

a. Linear Navigation Structure

The linear navigation structure is a navigation structure in which the user browses the program sequentially. 


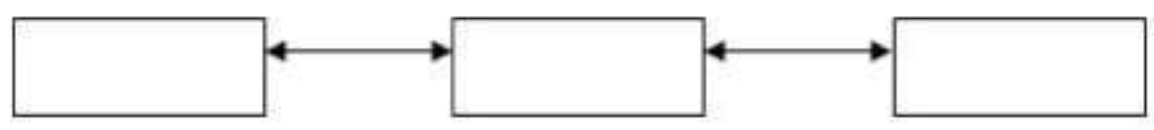

Figure 2.1. Linear Navigation

b. Hierarchical Navigation Structure

The hierarchical navigation structure is often called branched navigation structure, which is a structure that relies on branching to display data or images on layers with certain criteria. The display on the main menu is called the master page (main page one), the page has a branching page called the slave page (support page) and if selected it will become the second page, and so on.

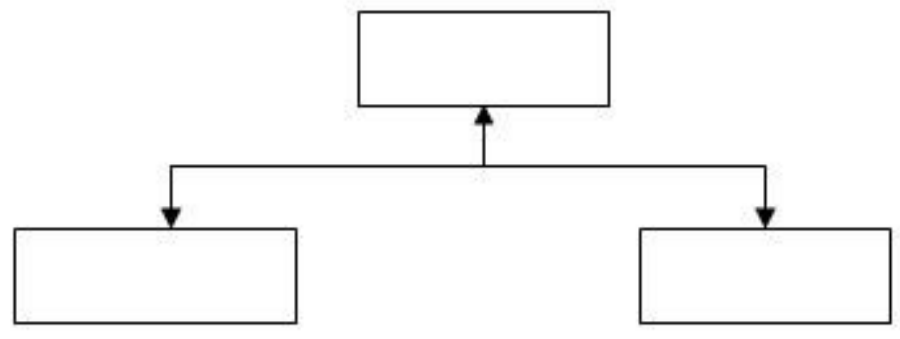

Figure 2.2. Hierarchical Navigation

c. Non-Linear Navigation Structure

A non-Linear navigation structure is a navigation structure where users are free to browse the program without being restricted by a route. Figure 2.3 is an image of a non-linear navigation structure.

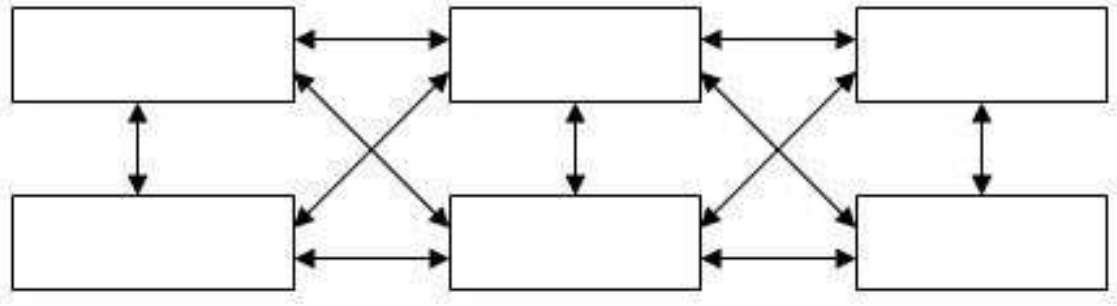

Figure 2.3. Non-Linear

d. Mixed Navigation Structure

A mixed navigation structure is a navigation structure resulting from mixing the previous navigation structure where the user can freely browse the program, but there are certain parts where the search is limited hierarchically or linearly.

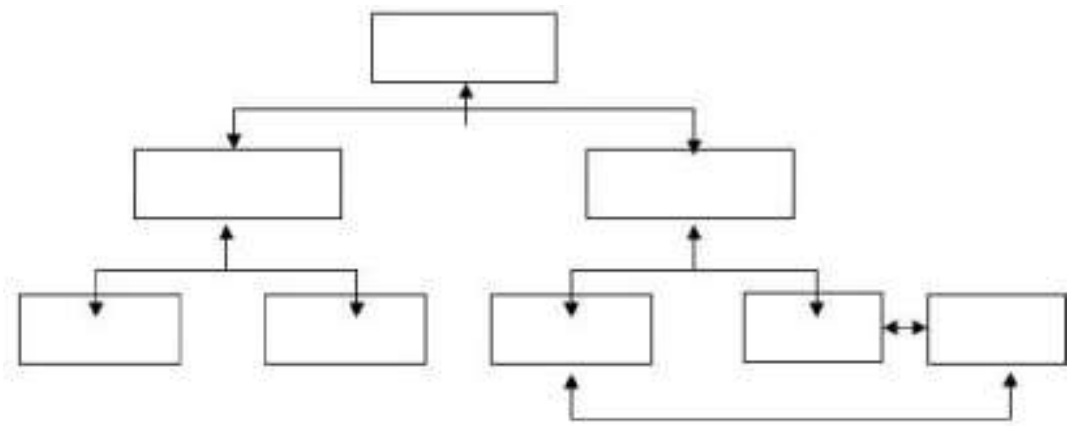

Figure 2.4. Mixed Navigation Structure

\section{Design and Implementation}

This system is built using native PHP for web programming. On this website, there are two user roles, namely admin and user. Each role has different access. Admin has access to manage all web features such as confirmation. Meanwhile, users have access to order tickets.

This system is made in accordance with the structure. When the user registers and logs in, the user is faced with ordering tickets. When the user orders a ticket, he is required to fill out a ticket form and make a payment transaction according to the intended 
account, after making a payment, a payment confirmation is required so that the admin checks if the money has been entered, the admin will confirm that the ticket has been ordered.

\section{A. Navigation Structure}

At this stage is the navigation structure of the web that will be made. The structure consists of two roles where the admin role is in Figure 3.1 and the user is in Figure 3.2:

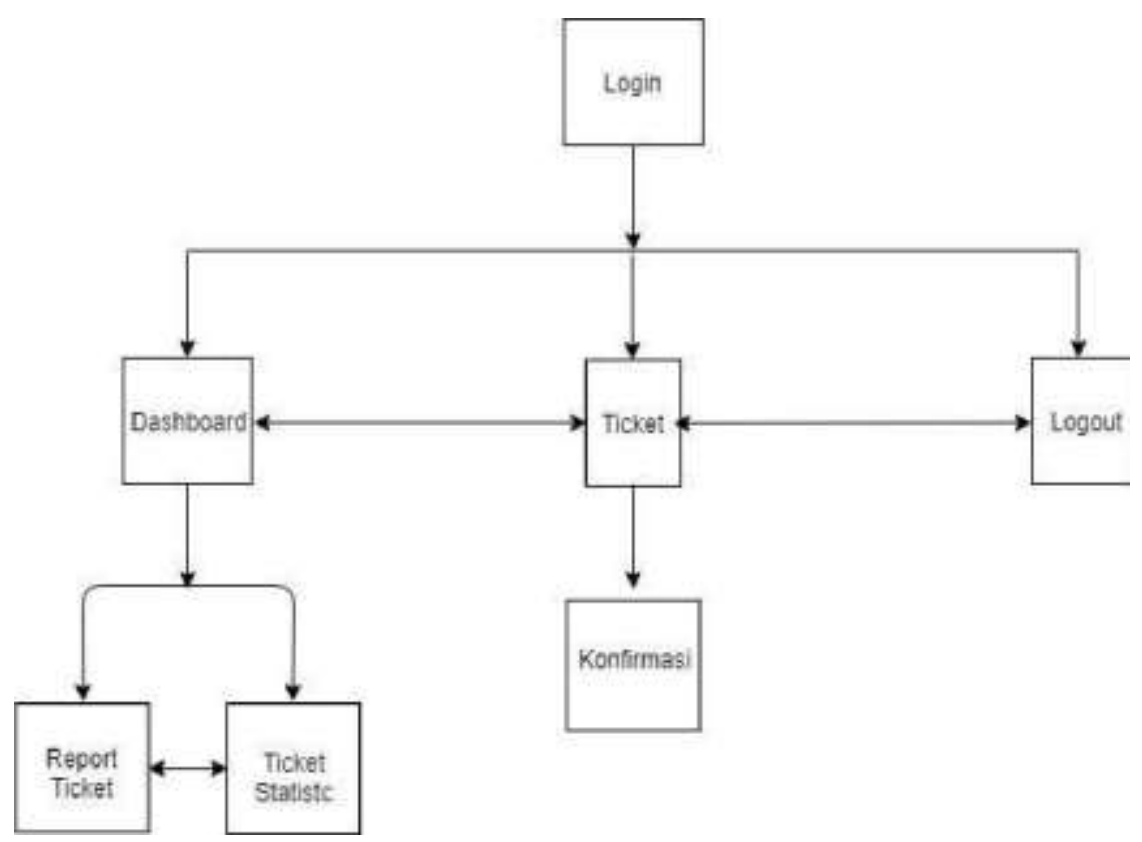

Figure 3.1 Admin Navigation Structure

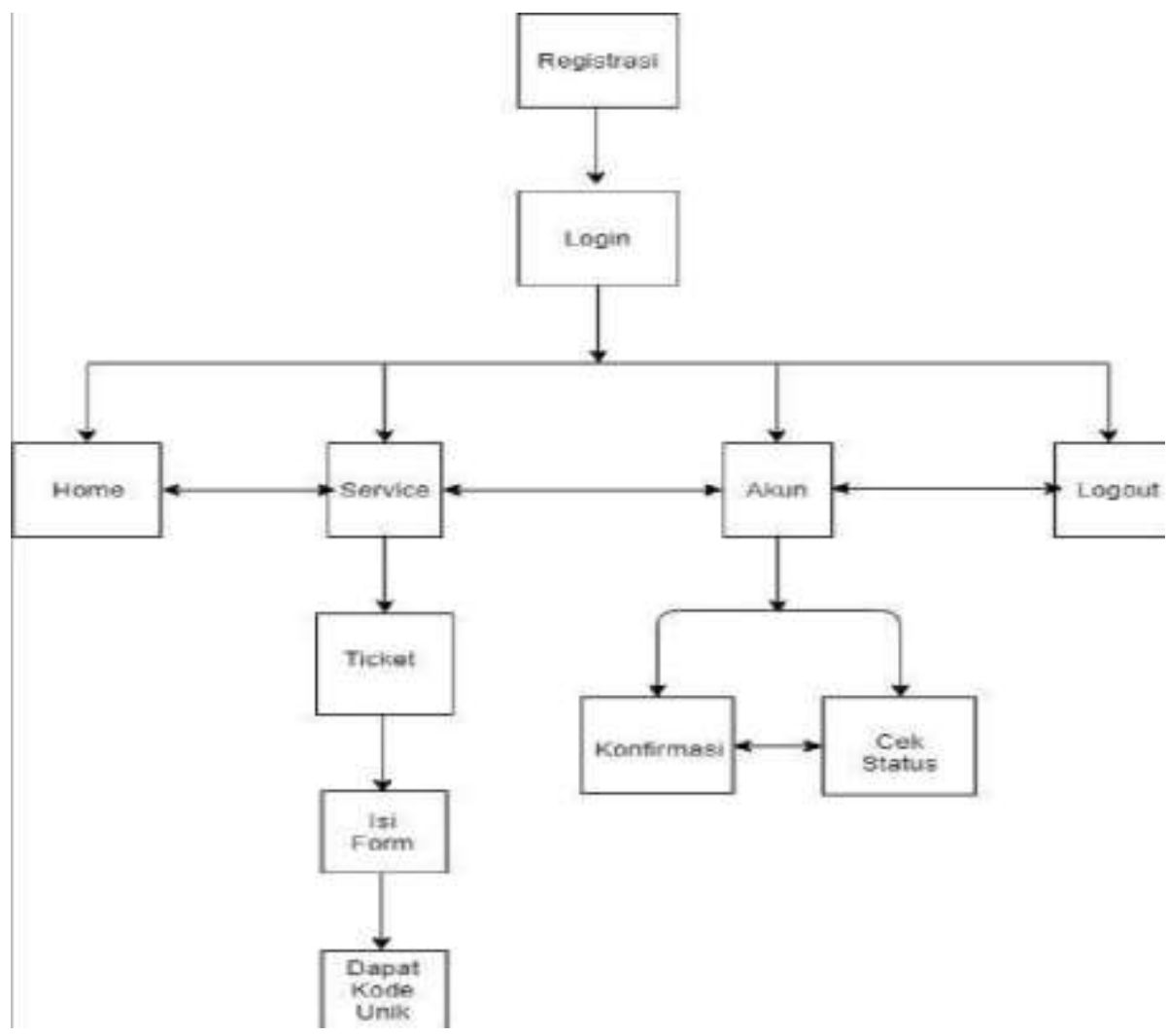

Figure 3.2 User Navigation Structure 
B. Web Design

In making the ticket purchase system an interface design is needed so that it can be easily used by users, in Figure 3.3 is a display home when the user enters the web address. On this page, there are several menu options, and there is also a little explanation of the flowers in the garden.

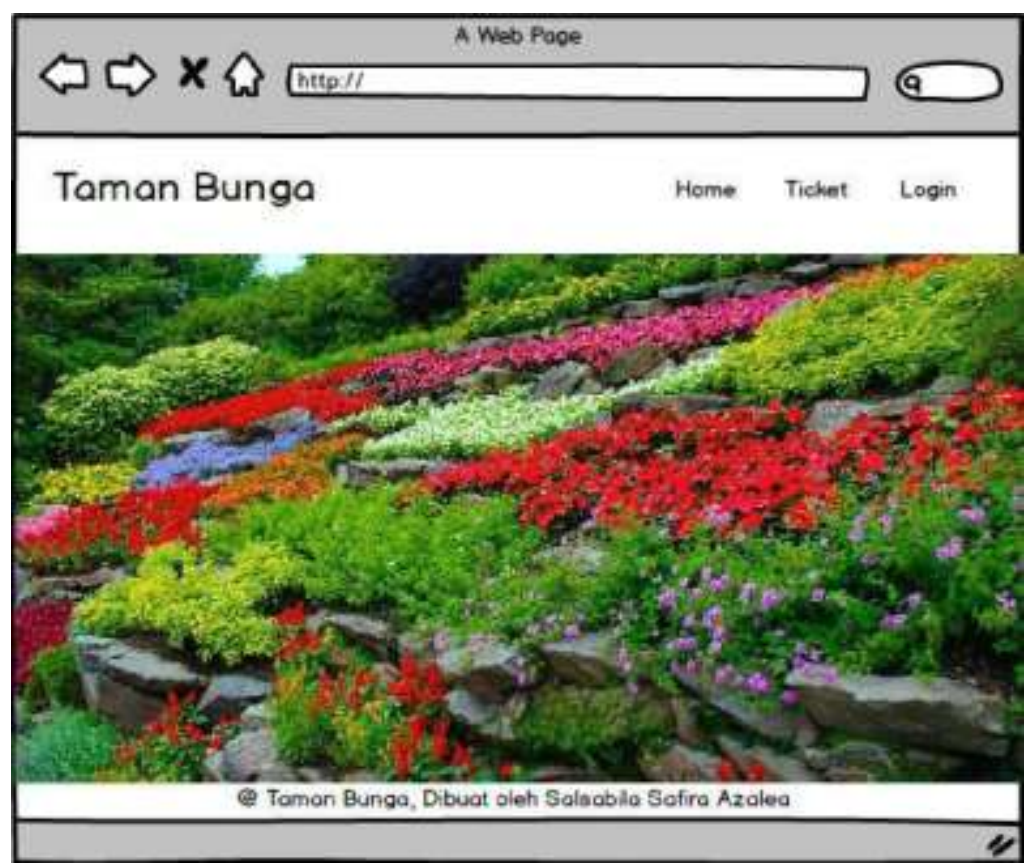

Figure 3.3 Mockup of the initial web display

Furthermore, Figure 3.4 is the display after the user selects the login menu. For users who already have an account, it is only enough to fill in the available fields, after pressing the Login button, it will return to the home or initial view of the web. However, if the user does not have an account, then select the Register text first. Then figure 3.5 shows the Registration page that the user uses to create a new account.

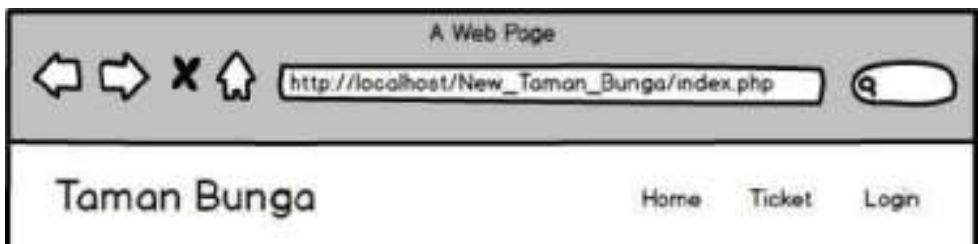

Login

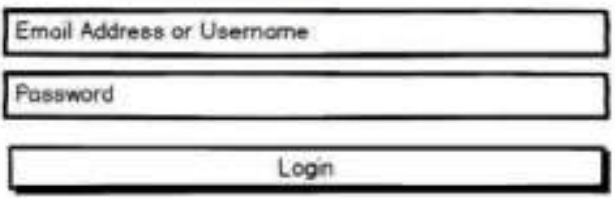

Don't have an occount? Regster here

Figure 3.4 Login Mockup 


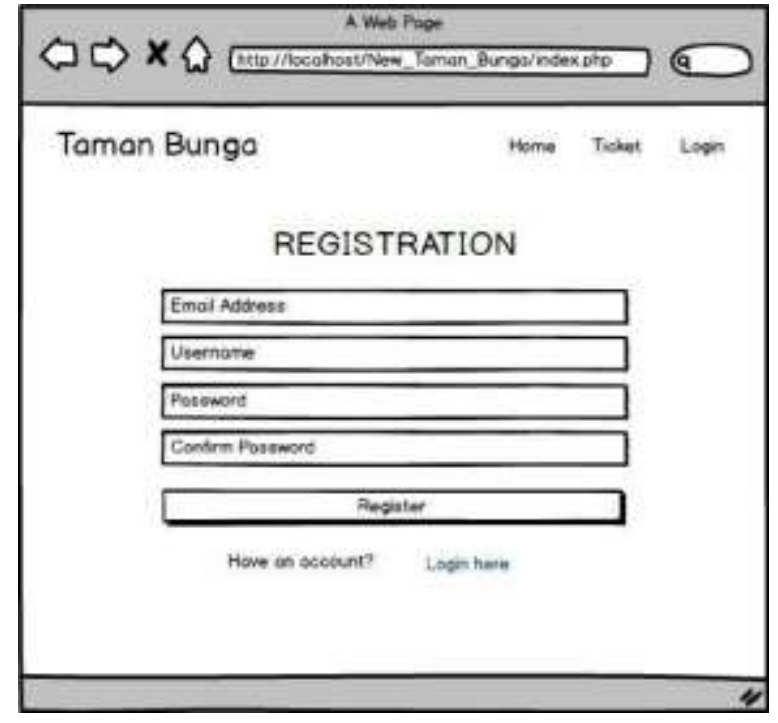

Figure 3.5 Registration Mockup

On this page, there are options to choose from, namely purchasing park entrance tickets. If the user selects the Ticket menu, it will go to Figure 3.6 which is a page to fill in the required data when ordering tickets. After that, in Figure 3.7 the data will be confirmed, where the user gets a unique code and the account number that is intended for payment.

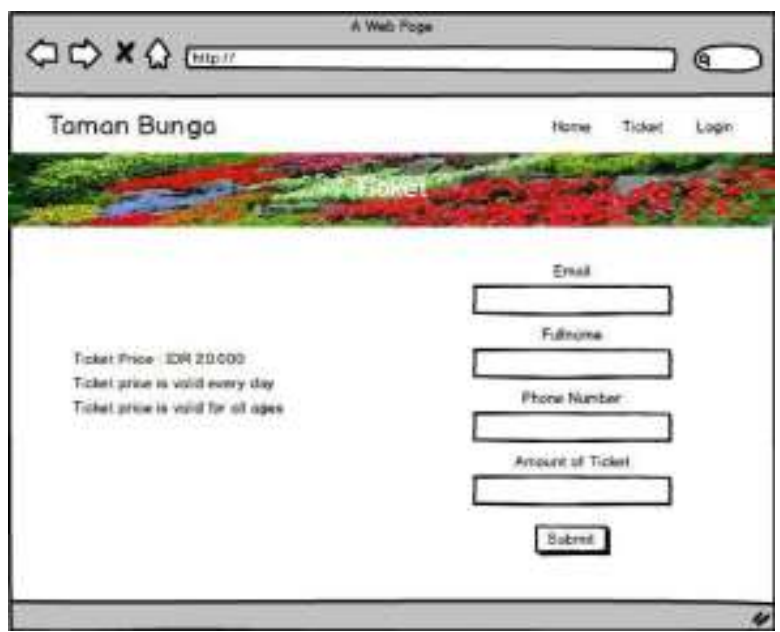

Figure 3.6 Ticket menu mockup

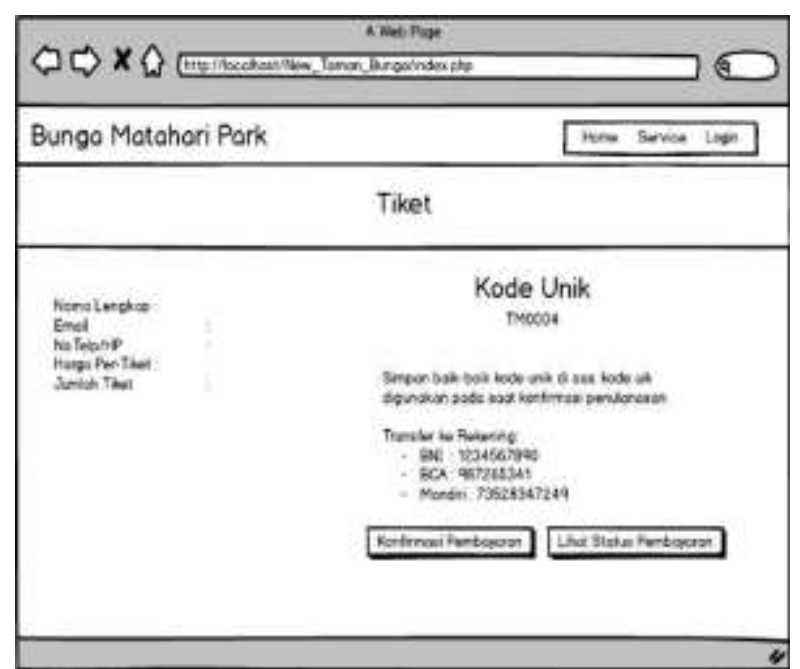

Figure 3.7 ticket booking confirmation mockup 
Furthermore, if you have received a unique code, you will get two choices of buttons, namely the payment confirmation button and view payment status where each button directs to each page, Figure 3.8 shows the payment confirmation page and the payment confirmation page. 3.9 shows the view payment status page.

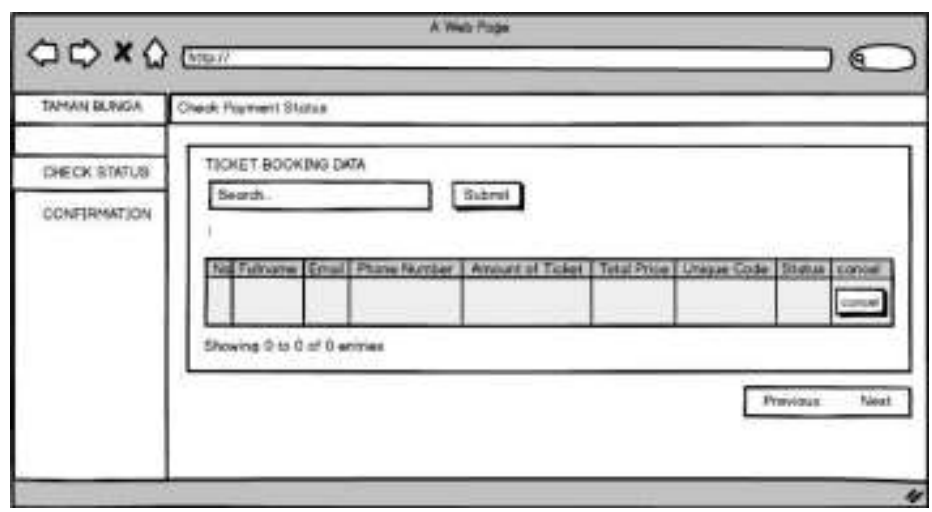

Figure 3.8 Check payment status mockup

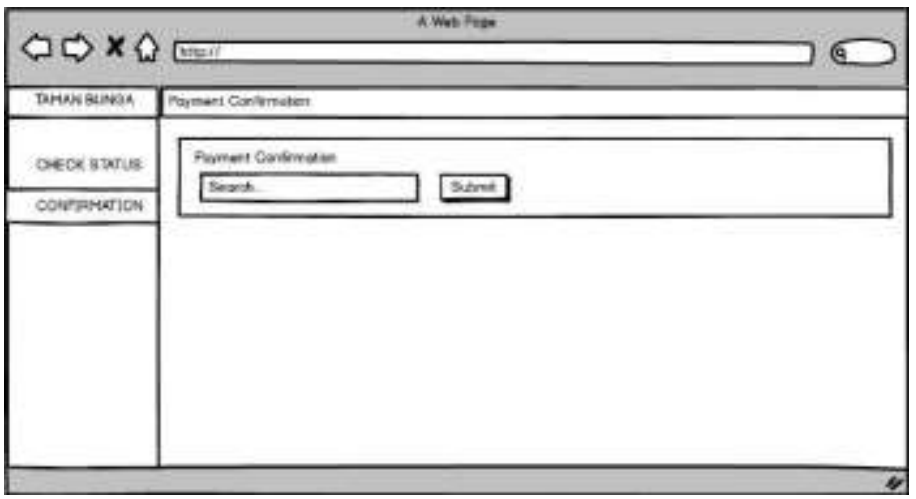

Figure 3.9 Payment confirmation mockup

Furthermore, if you have made a payment confirmation, you will wait for admin confirmation, therefore admins are required to check transaction data by logging in as admin in Figure 3.10, after logging in, they are immediately faced with the statistics page where the page This is a page that displays the number of ticket buyers per month. see Figure 3.11. Next on drawing 3:12 is a picture to confirm admin if the user has confirmed the payment then the admin will check the payment, if the payment has been entered the admin will confirm payment

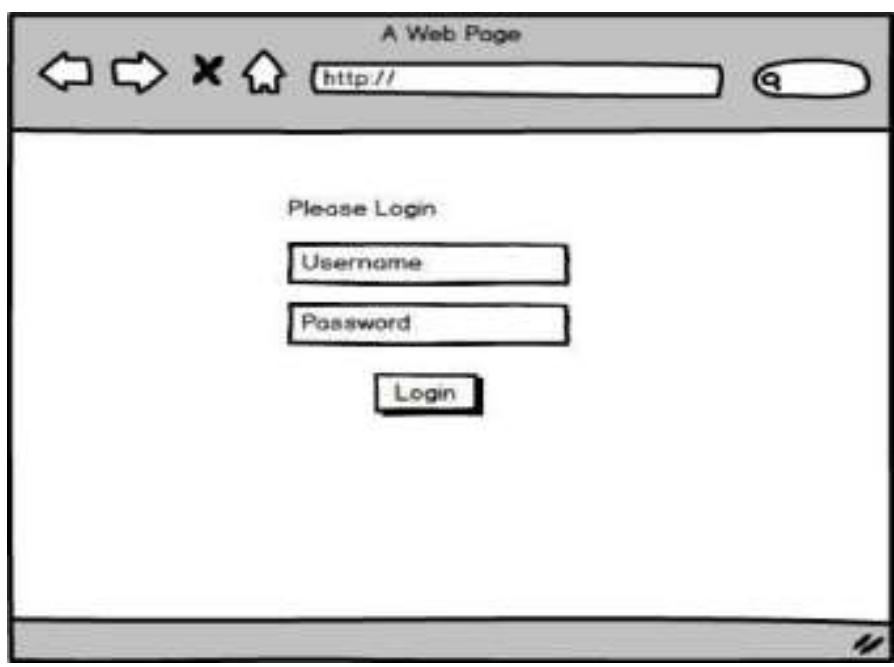

Figure 3.10 admin login mockup 


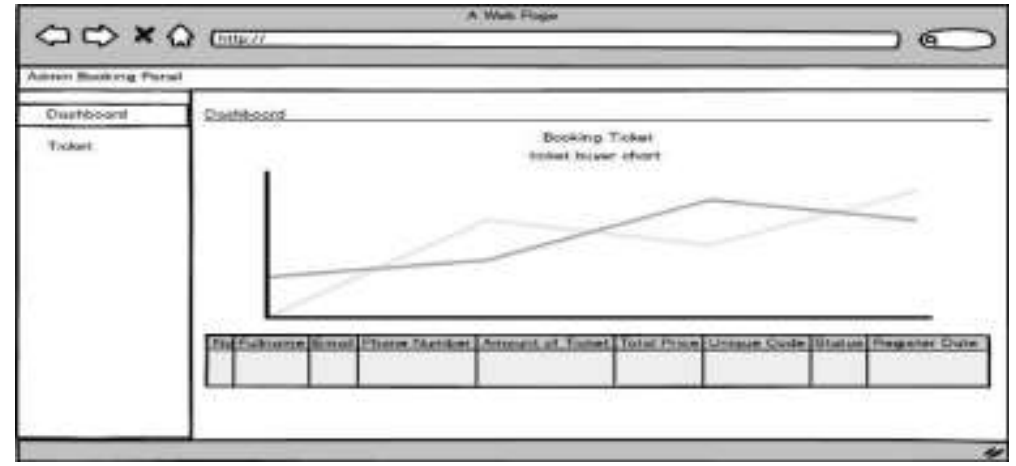

Figure 3.11 Statistics ticket buyers mockup

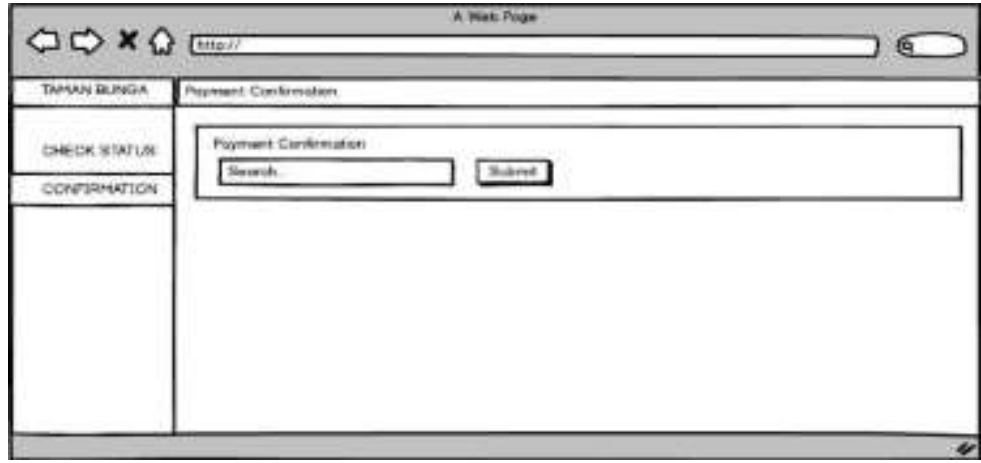

Figure 3.12 Payment confirmation mockup

C. Analysis with Flowchart

Flowchart of Flower Garden website, see Figure 3.13.

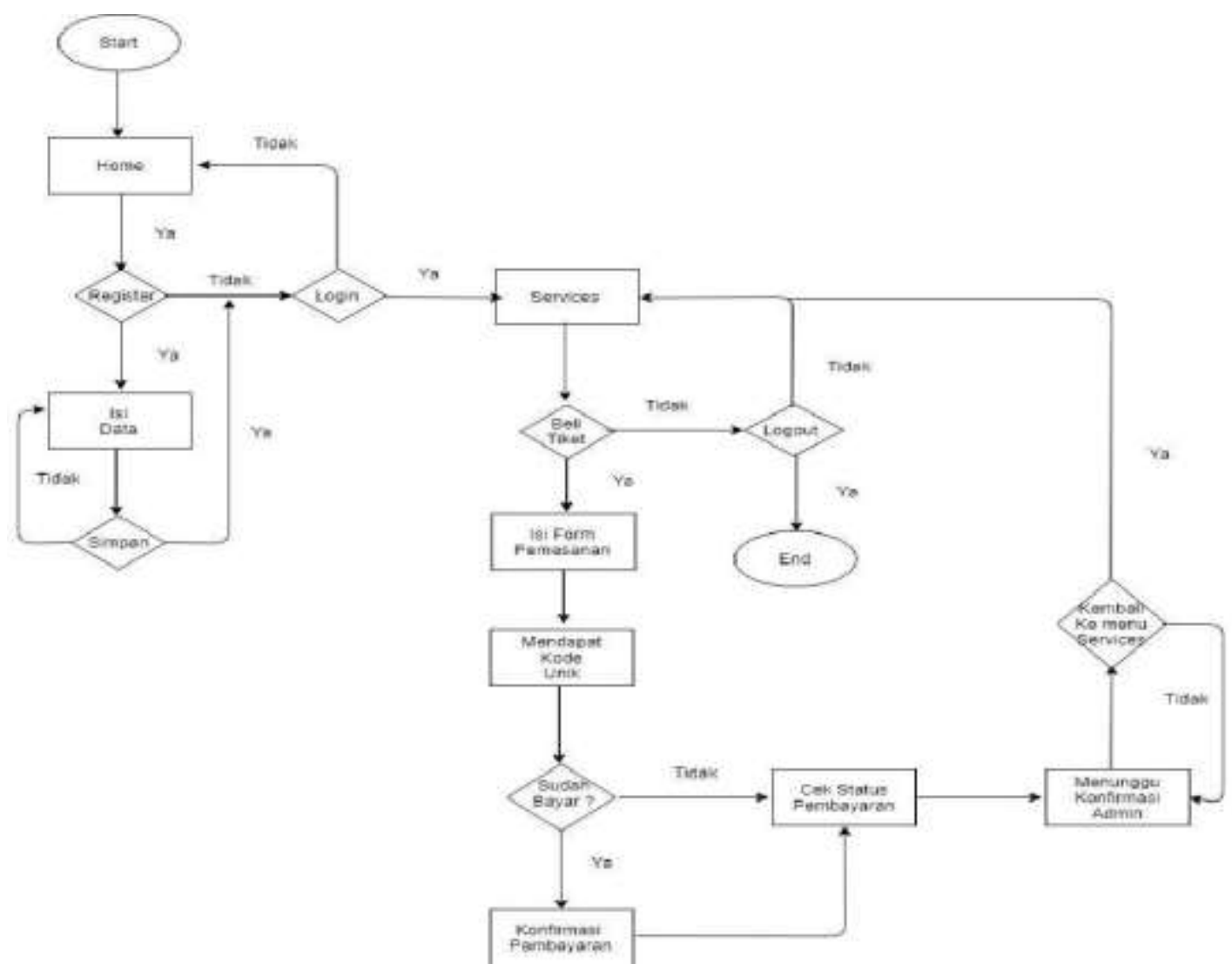

Figure 3.13 Web Flowchart 
D. Test

To test this system, it is required to use a laptop to run the web. The application webis run on a server local using the XAMPP Web Server with the application Google Chrome browser as a place to run the interface application. XAMPP WebServer is started by pressing the button start on the sections Apache and MySQL. The XAMPPconfiguration view is Web Server shown in Figure 3.14.

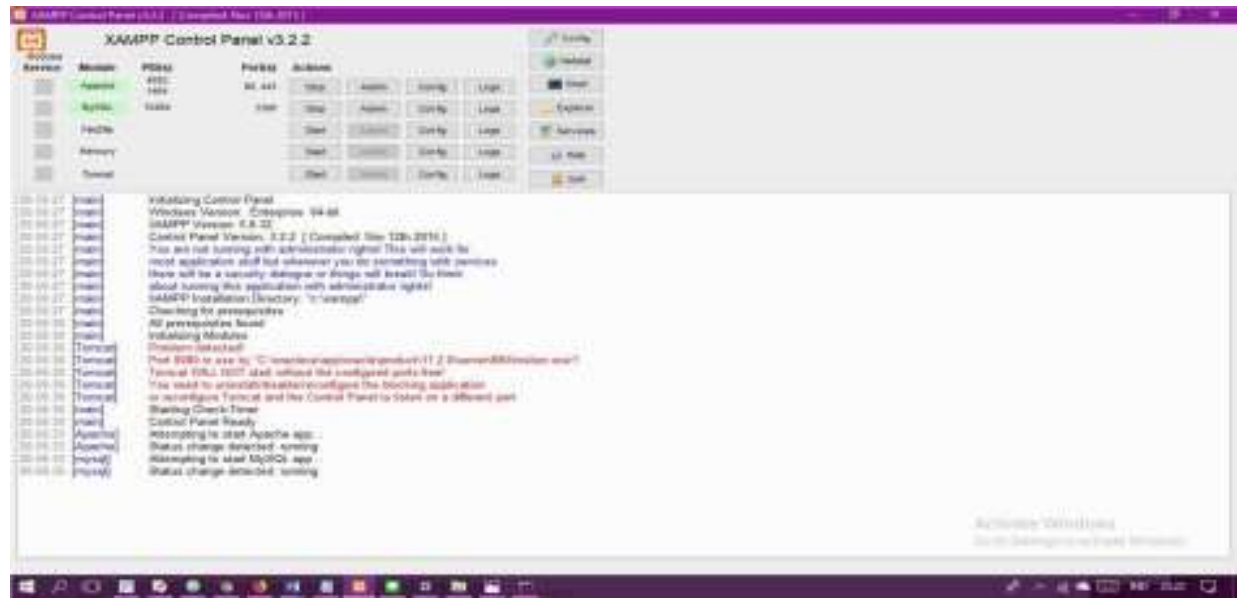

Figure 3.14 XAMPP Configuration Display

Next to test the application by running the Google Chrome browser. In the address bar write the URL according to the application folder stored in htdocs. The URL is http:// http://localhost/taman-bunga/index.php. The initial page display can be seen in Figure 3.15 .

\section{Taman Bunga}

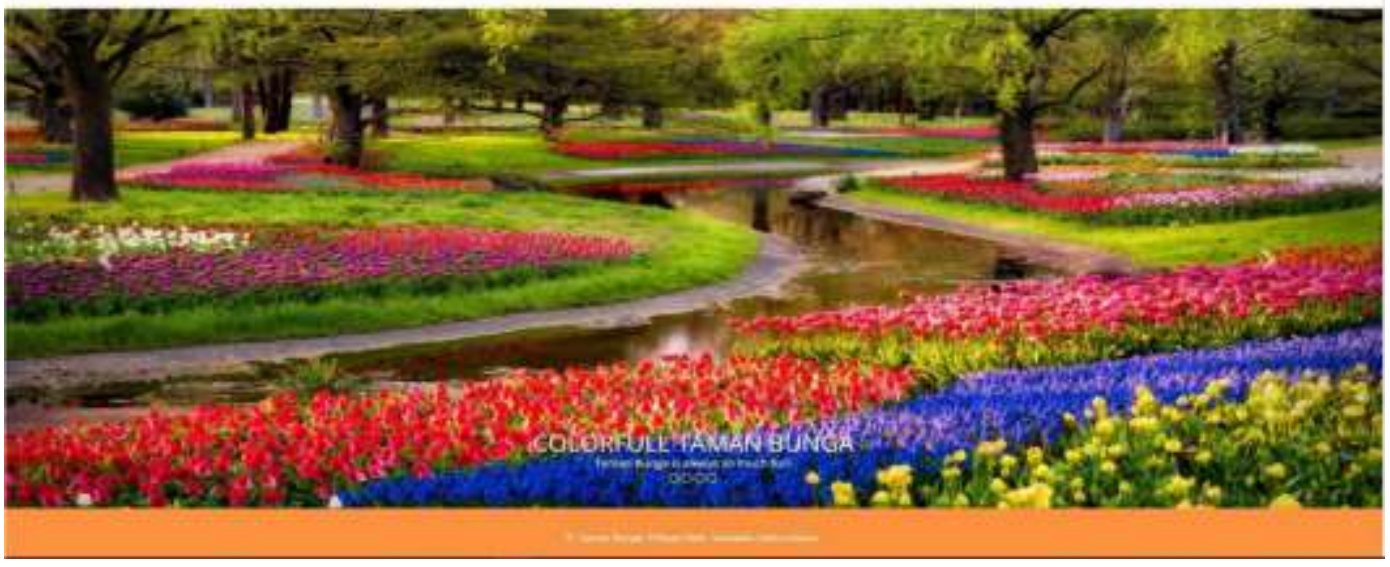

Figure 3.15 Main display

In Figure 3.16 the user is required to register first before entering the web system

$$
\text { Taman Blunga }
$$

Reginteration

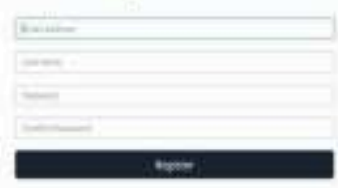

Figure 3.16 Display of web registration 
After registering, in Figure 3.17 the user is required to log in to enter the web system to order tickets

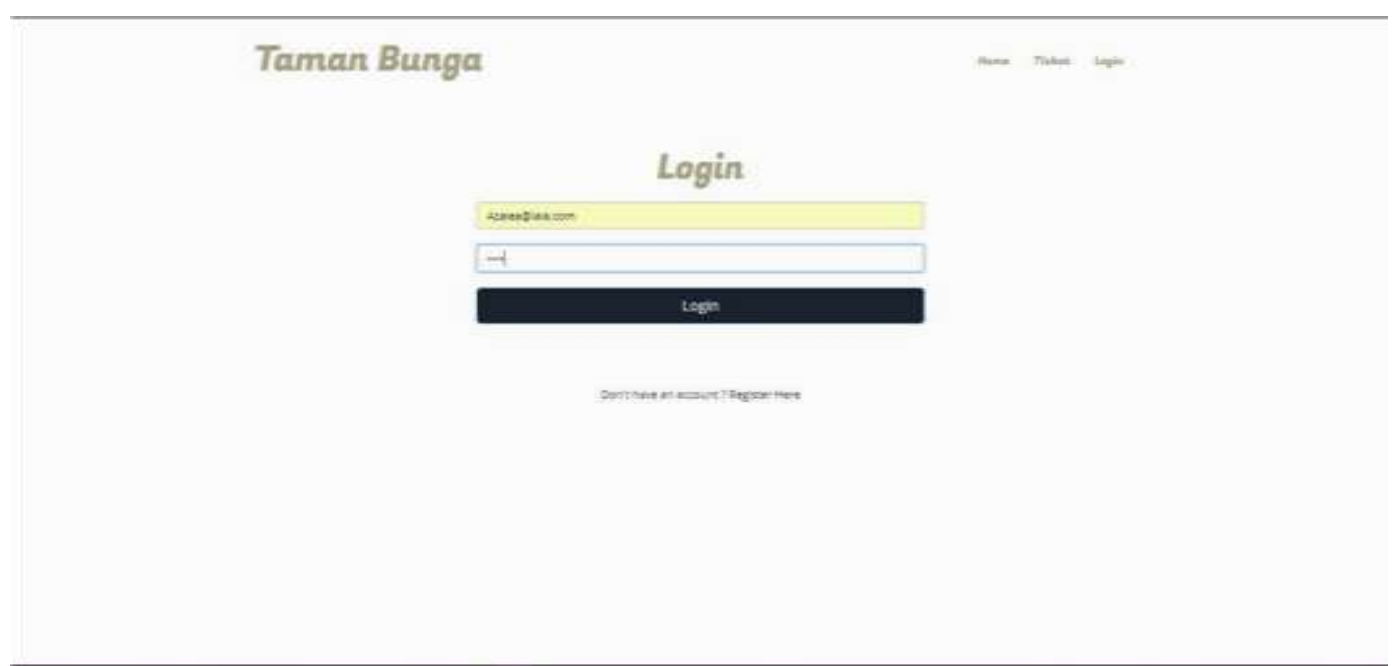

Figure 3.17 Login display

In Figure 3.18, when the user has logged in the user is immediately redirected to the ticket booking page, the user is required to fill in the email, full name, telephone number, and the number of tickets ordered
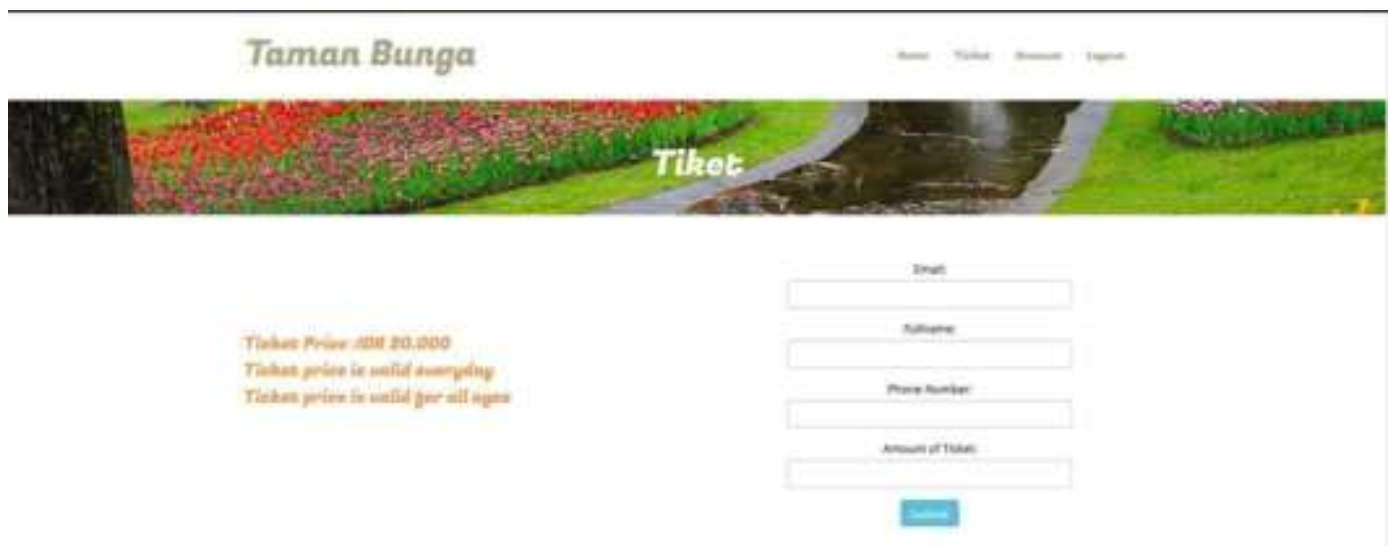

Figure 3.18 Ticket booking web display

After filling in the ticket reservation requirements, the user is required to transfer to the account listed, see Figure 3.19

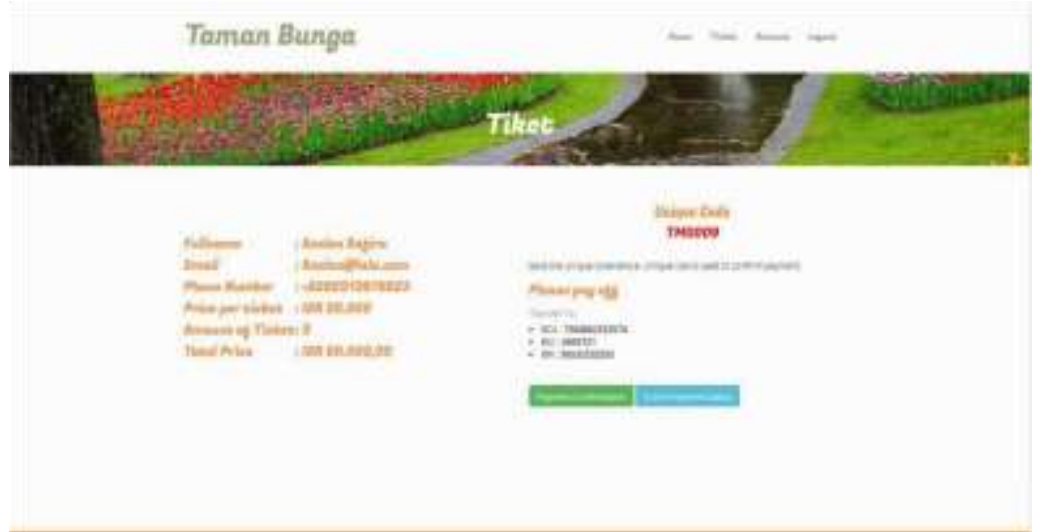

Figure 3.19 The web display displays a unique code. 
After that on the account menu, the user can check, if you have not paid for a ticket order, the order status will read pending, see picture 3.20

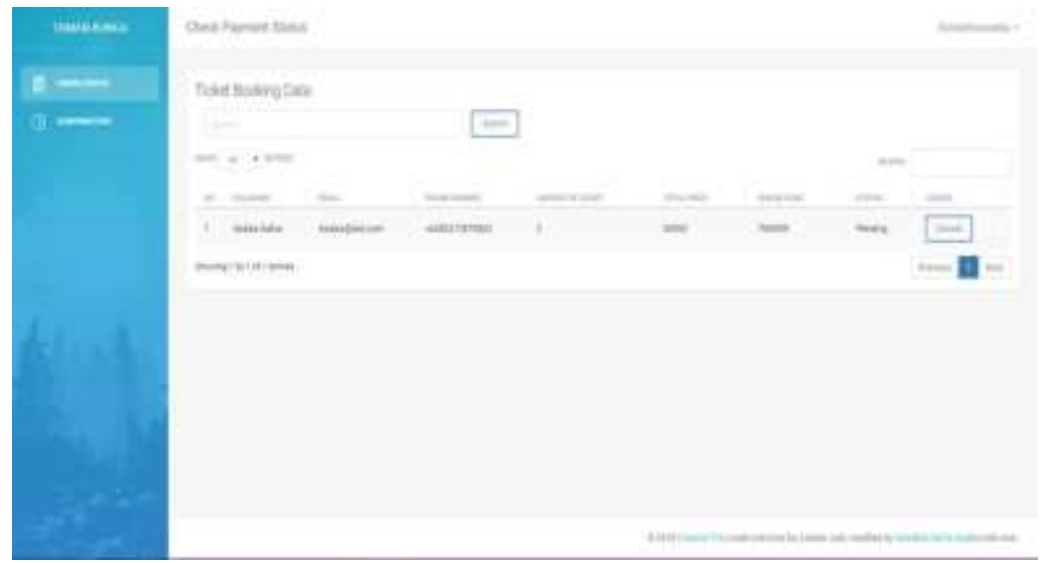

Figure 3.20 Display of ticket booking checks

If the user has paid or transferred money for ticket reservations, the user is required to input a unique code to send confirmation that the payment transaction has been made, see Figure 3.21

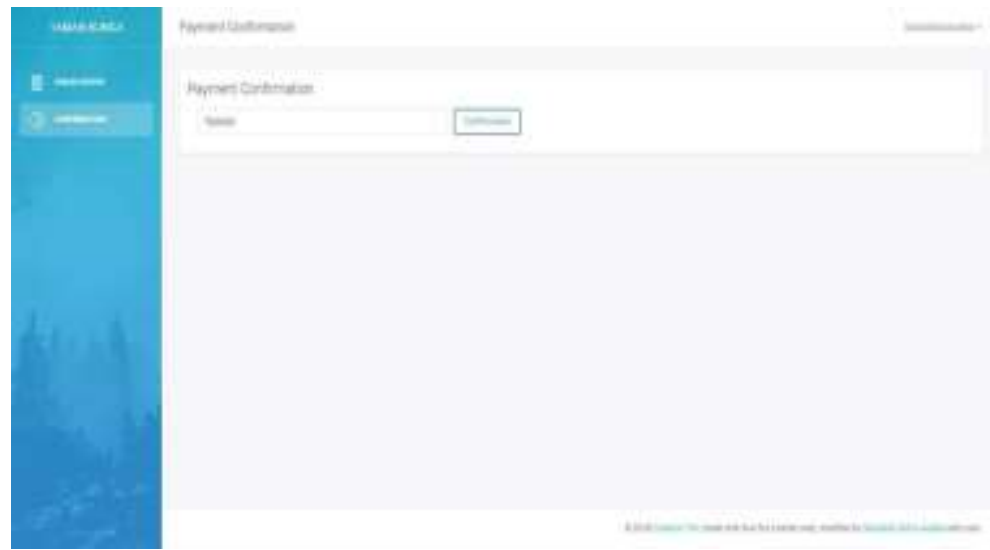

Figure 3.21 Display of ticket payment confirmation

In Figure 3.22 after confirming the payment, then the user is required to wait for the admin to confirm whether the money has been entered into the account

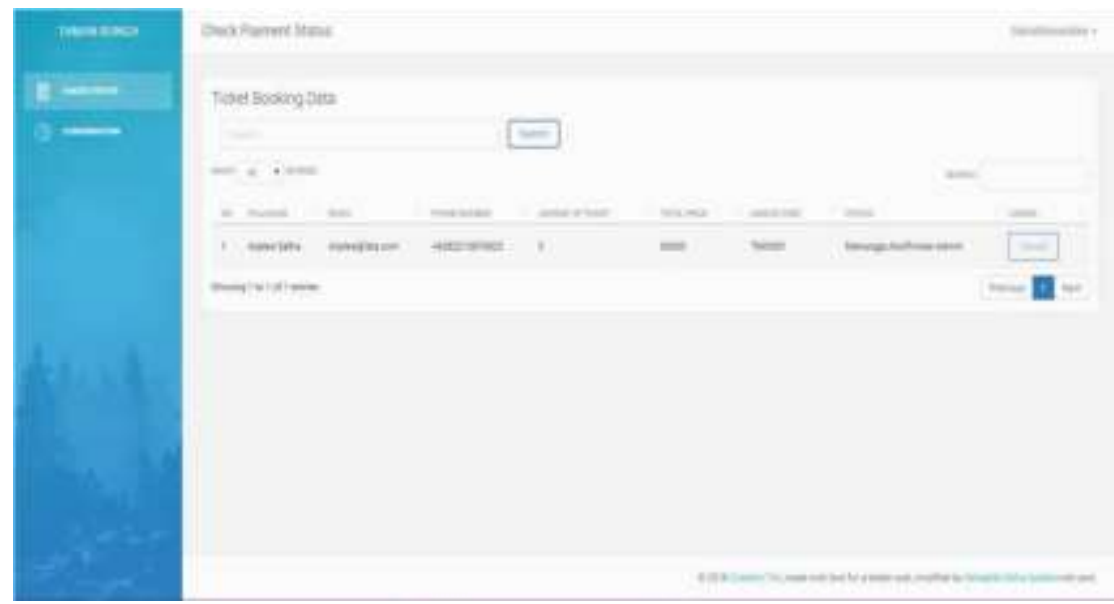

Figure 3.22 Web display waiting for admin confirmation 
In this section, for example, the admin will confirm a ticket order, then the admin is required to login first to the control panel, see Figure 3.23

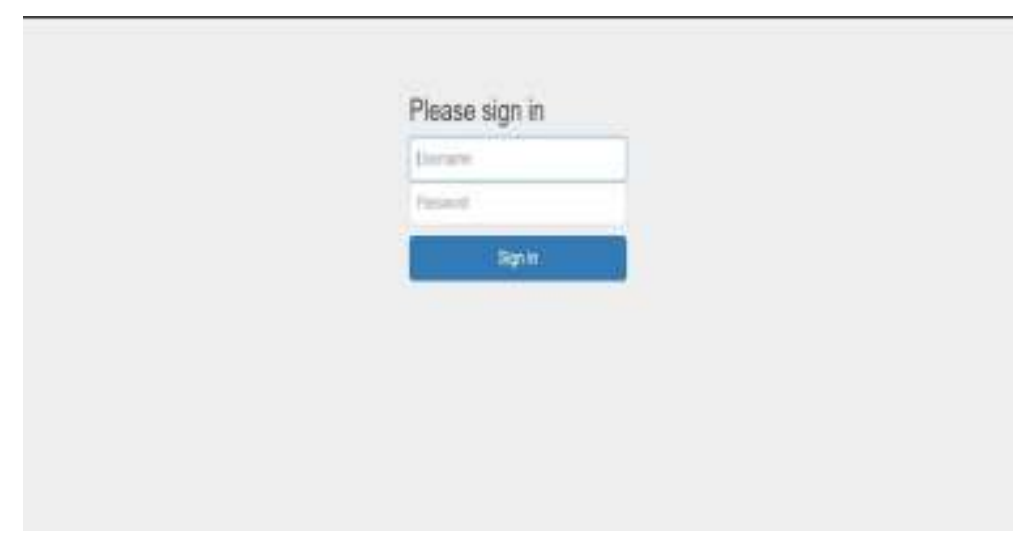

Figure 3.23 Admin login screen

After logging in, the admin will be faced with a dashboard display, see Figure 3.24

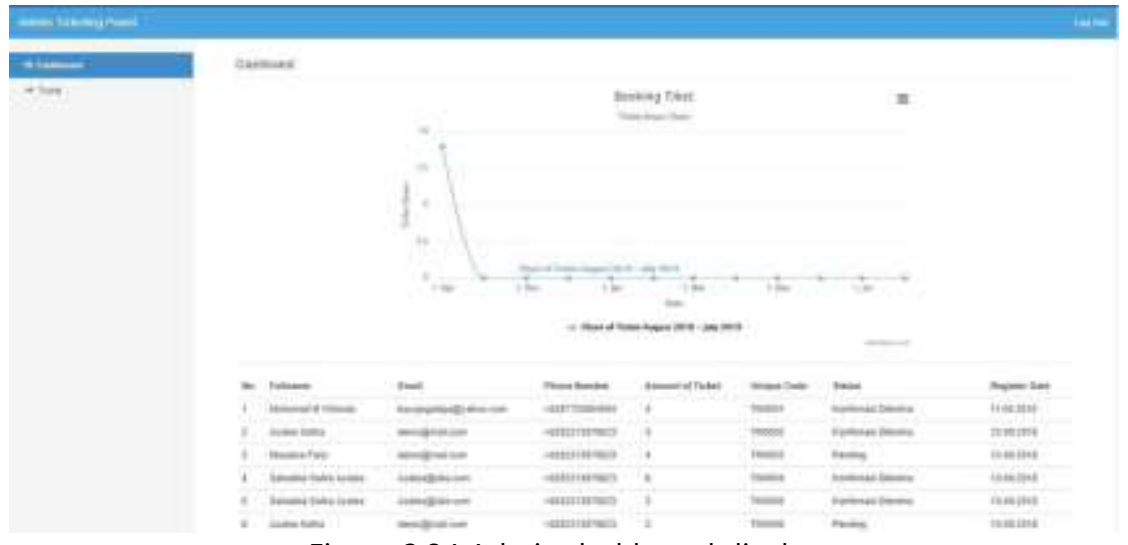

Figure 3.24 Admin dashboard display

After that, the admin confirms the ticket menu, see Figure 3.25

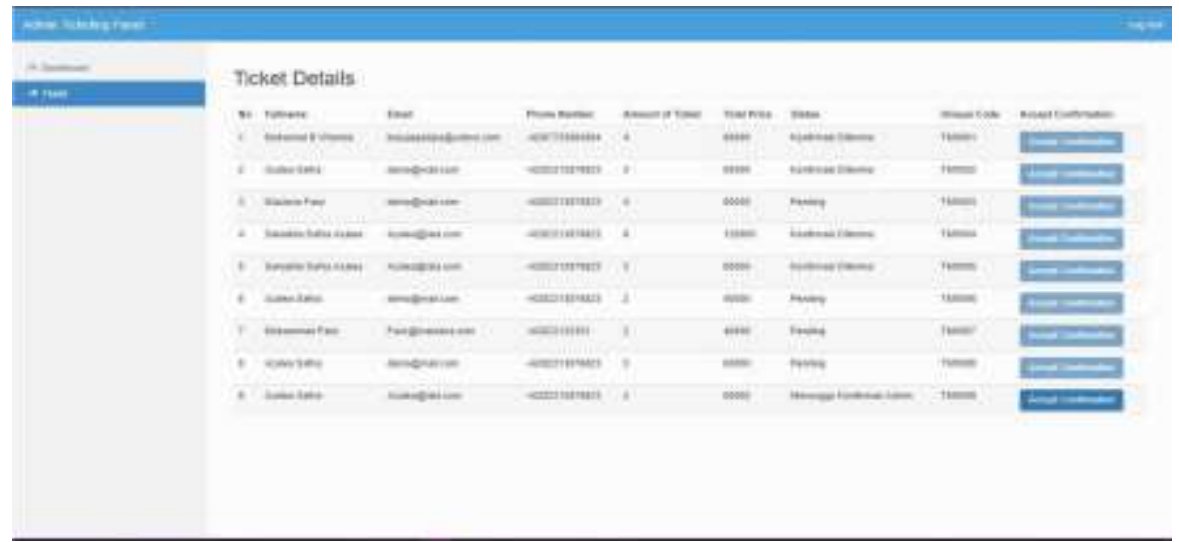

Figure 3.25 ticket

Next Display, on the user, display the payment status changes to the confirmation received, see Figure 3.26 


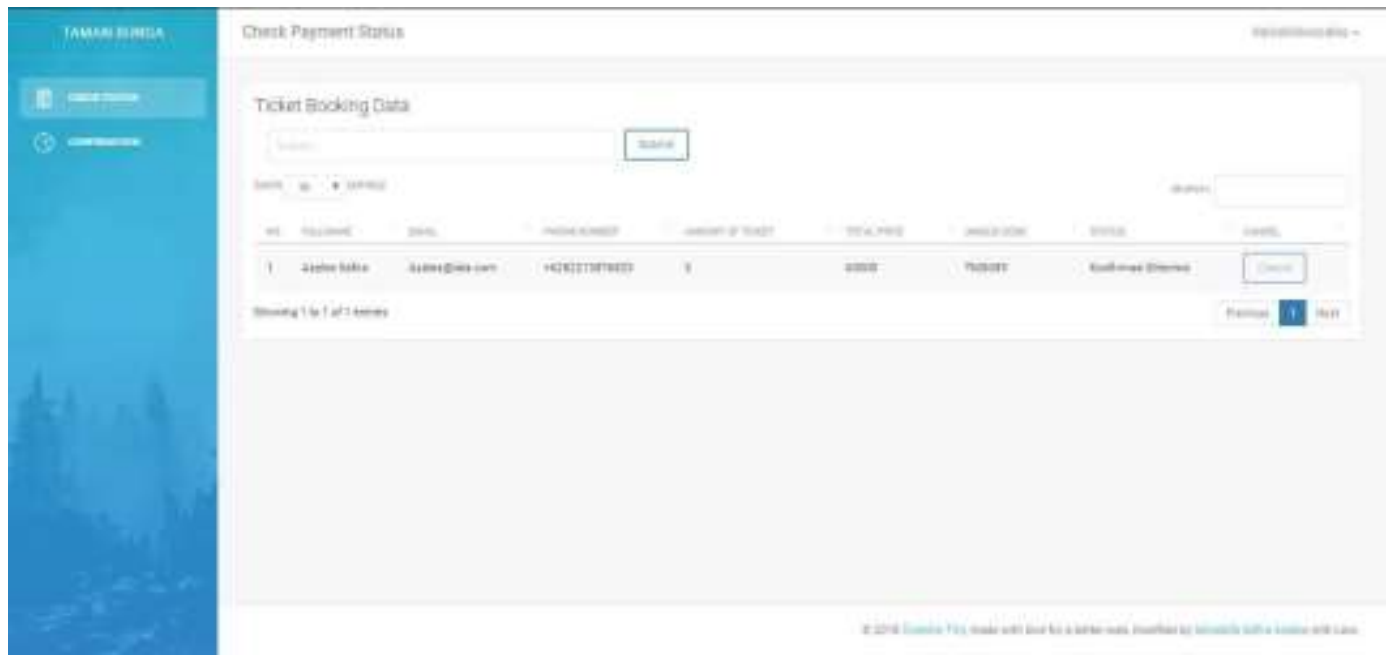

Figure 3.26 The status display changes

\section{Conclusion}

In this writing, it can be concluded that the online-based tourism ticket purchasing system was successfully created using native PHP for server-side and bootstrap as well as javascript for client-side. This system is designed for ordering tickets from anywhere, where when we order tickets we are required to register first and log in to enter the system, and when it has entered the system, the user can order tickets according to the desired amount and wait for admin confirmation so that the tickets can be used. . The implementation of a ticket booking system that is designed online can help the public in ordering tickets, so they don't have to wait in queues at the tourist spot.

\section{References}

[1] Alatas, H. (2013). Responsive Web Design With PHP \& Bootstrap. Yogyakarta: Lokomedia.

[2] Arief, M. R. (2006). Programming. Database Using Transact-SQL with Microsoft SQL Server 2000. Yogyakarta.

[3] Arief, M.R (2011). Dynamic Web Programming Using PHP \& MySQL. Yogyakarta: Andi.

[4] Djaelangkara, R. T, Sengkey, R and Lantang, O. A (2015). Design of a WEB-based School Academic Information System Case Study of Christian High School 1 Tomohon. Electrical and Computer Engineering.

[5] Haviludin. (2011). Understanding the Use of UML (Unified Modeling Language), Journal of Informatics vol 6(1).

[6] Hidayatullah, P. and Kawistara, J. K (2015). Web Programming. Bandung: Informatics.

[7] Muljadi A. J (2009). Tourism and Travel. Jakarta: Rajawali press.

[8] Leitch, R. A and Davis, K. R (2001). Information Systems. Jakarta: PT. Prenhallindo 